\section{On the Combustion of Different Kinds of Fuel}

I HAVE read with interest the criticism of Mr. I. Lowthian Bell (NATURE, vol. xix. p. I75) on my paper on the mode of combustion in the blast furnace hearth. You say with truth that the question is not simply technical, but is one of scientific importance. The prevailing opinions, which Mr. Bell has expressed with his usual force, rest upon experimental determinations of the gases in the hearth. I have never felt that trustworthy results have been obtained in any of the published analyses, and with your permission I would like to state the case, and see if my difficulties are removable by the wide experience of Mr. Bell or other investigators.

The blast-furnace hearth is a cylinder, closed at the bottom, but perforated near the top by a number of openings in which the tuyeres, or ends of the air blast-pipes are closely fitted. The air enters at a pressure which usually varies in anthracite practice between four and seven pounds to the square inch. As the discharge is at the top of the furnace, many feet higher, the air must describe a curved path from the point of entrance to the centre of the furnace, being acted upon continuously by a horizontal and a vertical force. It is evident that the level of the tuyeres is not the place to obtain the first products of combustion unless they are drawn through a tuyere in action. Elsewhere the samples would not be taken from the path of the air, which is upward from the tuyere from the instant it enters the hearth.

Mr. Bell and other investigators have analysed gases drawn from the hearth by means of porcelain tubes introduced through a closed tuyere aperture, or through holes drilled between the tuyeres. It seems to me these analyses are vitiated by the mode of drawing off the gas, and since this criticism applies to the experimental basis of existing views of combustion in confined spaces and with limited supplies of air, I will give a few details to show the scope of my objection.

At the Wear furnace Mr. Bell drew off gas through a tuyere that was closed for the purpose, but air was entering at other tuyeres on each side and four feet distant. Certainly this did not represent the product of that active combustion which takes place in the path of the air, but of these products after they had filtered through nearly four feet of glowing fuel. What the exact distance was depends upon the velocity of gas in the crucible of the Wear furnace and the inner diameter of the hearth, but was probably over three feet.

The quantity drawn off is not mentioned, but as it was taken for eudiometric analysis, the amount was probably less than five litres, and the movement of the gas through this glowing coal to the sample tube must have been extremely slow. Under these circumstances, whatever the product of combustion in the path of the air may have been, there could be only one gas drawn into the sample tube, and that would be carbonic oxide mixed with nitrogen. Even if we assume that the product of combustion in the furnace is carbonic anhydride alone (which is not true), this would be completely reduced to carbonic oxide by passing through the hot coal.

The experiments made on gas which was drawn through tubes in holes inserted between the tuyeres do not impress me more favourably. There the tubes were thrust "a little way into the contents of the furnace." That description does not apply to the mode in which gas samples were drawn off for analysis, but to experiments for testing the reducing powers of the gas by submitting pieces of ore to its action. Still it is probably also the mode in which samples were obtained, and the object of this note is to ascertain whether more careful means of sampling the unchanged products of combustion were used. If not, I submit that the analyses which form the basis of all modern reasoning on this subject must be rejected. The rapidity with which red hot carbon reduces carbonic anhydride, and produc $s$ just the gas which experimenters find in their sample tubes, is well known, and methods of sampling which take no rrecautions to guard against this change cannot be accepted. I think the investigators owe it to science to give the world some hint of the means they have used to prevent this action, and to obtain the gas as it is formed. In the case of one of our American fumaces-a small on - the blast has an upward velocity of twenty feet per seco:d at the level of the tuyeres, without considering the increase of volume by its rise in temperature in the furnace, and also allowing it to penetrate instantly to the centre, so as to cover the whole ar a of the crucible. That cannot be true, and on the other hand the withdrawal of gas from the walls at the tuyere level, while the air is entering with great velocity four feet away, can hardly give a fair sample of the unaltered result of immediate combustion.

Columbus, Ohis, U.S.A., January $2 \mathbf{I}$

JOHN A. CHURCH

\section{Internal Resistance}

THE following method of measuring the internal resistance of a battery was devised some two years ago by Lieut. A. R. Conden, United States Navy, then attached to this station as Instructor in Electricity. It fulfils quite closely the conditions indicated by Clerk Maxwell on p. $4 \mathbf{1 2}$, vol. i. of his treatise on Electricity and Magnetism. As it is not generally known, I venture to call your attention to it.

In the figure, $\mathrm{B}$ is the battery, $\mathrm{G}$ a galvanometer, $\mathrm{R}$ and $\mathrm{R}_{\mathbf{1}}$ resistances, $K^{\prime \prime}$ a key for introducing the shunt $S$, and ' $K^{\prime}$ another key for shunting out the resistance $\mathrm{R}$.

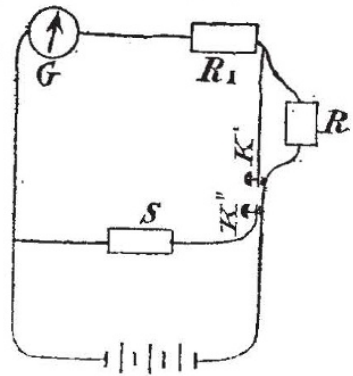

$B$

When both keys are open the current through the galvanometer is-

$$
S_{1}=\frac{E}{B+G+R+R_{1}}
$$

When both keys are closed the current from the battery divides, part going through $\mathrm{G}$ and $\mathrm{R}_{1}$, part through $\mathrm{S}$. The current through the galvanometer is now-

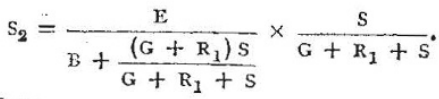

If $s_{1}=s_{2}$, then-

$$
\frac{E}{B+G+R+R_{1}}=\frac{E}{B+\frac{\left(G+R_{1}\right) S}{G+R_{1}}+S} \times \frac{S}{G+R_{1}+S} .
$$

Solving for $\mathrm{B}-$

$$
\mathrm{B}=\mathrm{S} \frac{\mathrm{R}}{\mathrm{G}+\mathrm{R}_{1}} .
$$

Finally, if $\mathrm{R}$ have been adjusted equal to $\mathrm{G}+\mathrm{R}_{1}$, then-

$$
\mathrm{B}=\mathrm{s} \text { directly. }
$$

In practice $R$ is a rheostat unplugged to equal $G+R_{1}$, and the two keys are combined in one. If the current be small enough with $G+R$ then $R_{1}$ may be omitted and $R$ made equal to $G$. $S$ is adjusted until, apon closing the double key, the deflection of the needle remains unchanged. The resistance of the battery is then the resistance of the shunt.

The case and concordance of the results obtained in this way through long series of measurements are no less striking than the rapidity with which the observations may be made.

Torpedo Station, Newport, R.I., C. F. GoODRICH January 12

\section{The Formation of Mountains}

MR. G. DARwIN has shown that, on the supposition that the earth is a cooling solid, the depth at which the maximum cooling and consequently, in all probability, the maximum contraction takes place, moves downwards, and, taking Sir W. Thomson's values of the constants, has not yet got down so far as ico miles.

This shallowness of the layer hitkerto chiefly affected is alone sufficient to prove how small an effect can be attributed to such a cause.

He inquires whether I may not have under-estimated the contraction of rock in cooling. In my calculation I put it at 000007 linear for one degree Fahr. I derived this estimate from 